\title{
A NEW METHODOLOGY FOR DIAGNOSIS OF FANCONI ANEMIA BASED ON BIOLOGICAL DOSIMETRY
}

\begin{abstract}
Amaral A
Ph.D. in Radiobiology from University of Paris XII-France; M.Sc. in Nuclear Technology from the Federal University of Pernambuco; Full Professor at the Nuclear Energy Department from Federal University of Pernambuco and head of the Laboratory of Modeling and Applied Biodosimetry; Avenida Prof Luiz Freire, 1000, Cidade Universitária 50740-545, Recife, Pernambuco, Brasil; amaral@ufpe.br; https://orcid.org/00000003-4513-1701
\end{abstract}

\section{De Lima SC}

Ph.D. in Applied Health Biology and M.Sc. in Nuclear Technology from the Federal University of Pernambuco; Professor at the Uninassau, Campina Grande; suelenlima.lp@ gmail.com; https://orcid.org/0000-0003-3793-5152

\section{Silva LMB}

M.Sc. in Nuclear Technology and Bachelor in Biomedicine by the Federal University of Pernambuco; Biologist at the Laboratory of Modeling and Applied Biodosimetry, Nuclear Energy Department from Federal University of Pernambuco; leone_maltz@live.fr; https://orcid.org/0000-0002-5736-1464

\section{Lemos-Pinto $M$}

Ph.D. in Nuclear Technology and M.Sc. in Genetics by the Federal University of Pernambuco; Professor at University of Mauricio de Nassau; marcelazoo@gmail.com; https://orcid.org/0000-0002-6675-9875

\section{Lucena LRF}

M.Sc. in Genetics and Plant Breeding from University of São Paulo; Bachelor in Biology from Federal University of Pernambuco; Biologist at the Laboratory of Modeling and Applied Biodosimetry, Nuclear Energy Department from Federal University of Pernambuco; Irf.lucena@gmail.com; https://orcid.org/0000-0002-0905-1483

\section{Marques-Salles T}

Ph.D. in Medical Genetics by Federal University of Pernambuco; Specialist in Hematology from the Brazilian Society of Hematology and Hemotherapy; Physician at the Oswaldo Cruz Hospital, University of Pernambuco; terezinhajms20@gmail.com; https://orcid. org/0000-0001-6728-2813 


\section{Silva EB}

Ph.D. by University of São Paulo; M.Sc. in Nuclear Technology by the Federal University of Pernambuco; Professor at the Academic Center of Vitoria, Federal University of Pernambuco - Vitória de Santo Antão; edvborges@yahoo.com; https://orcid.org/00000001-7839-9945

\section{Magnata SP}

Ph.D. and M.Sc. in Nuclear Technology from the Federal University of Pernambuco; Professor at Academic Center of Vitoria, Federal University of Pernambuco; Professor at the Academic Center of Vitoria, Federal University of Pernambuco - Vitória de Santo Antão; sfmagnata@terra.com.br; https://orcid.org/0000-0002-7496-8386

Abstract: Fanconi Anemia (FA) is a syndrome associated with chromosomal fragility. Current laboratory tests to diagnose this disease are based on the scoring of chromosomal aberrations induced in peripheral blood lymphocytes by clastogenic chemical agents, mainly: diepoxybutane (DEB) or mitomycin $C(M M C)$. This study evaluated an alternative test for the diagnosis of $F A$, in which ionizing radiation replaces DEB/MMC. Two groups were studied: normal and DEB-sensitive individuals. From each individual, samples of peripheral blood were irradiated using an electron linear accelerator. Following lymphocyte cultures, and slide preparation, metaphases were scored based on the same methodology for biological dosimetry, according to recommendations of the International Atomic Energy Agency. Our results emphasized a pattern of distribution of dicentrics, fragments, as well as abnormal chromosomal arrangements. The methodology of analysis here proposed permitted to distinguish normal from DEB-sensitive subjects.

Keywords: Fanconi Anemia. Chromosomal Fragility. lonizing Radiation. DEB-test. MMC.

\section{INTRODUCTION}

Fanconi Anemia (FA) was firstly described by Guido Fanconi in 1927, after clinical observation of 3 brothers who presented aplastic anemia and similar clinical signs, such as hyperpigmentation and physical abnormalities.' Primarily described as a rare autosomal recessive disease due to an increased incidence in families with blood ties, studies involving similar cases in families that had no inbreeding revealed an FA subtype, which is X-linked recessive. The overall prevalence of FA is around 1:100,000 for homozygous, and the average life expectancy is about 20 years. ${ }^{2-4}$

Clinical manifestations of FA include small stature, congenital malformations, skin hyperpigmentation, pancytopenia, predisposition to neoplasia, and cancer, especially 
hematological malignancies and solid tumors of the head and neck. The myriad of phenotypes involved in FA implies that the diagnosis of this disease, based only on clinical features, is not straightforward and is often dubious. At the cellular level, FA individuals present severe chromosomal fragility, with spontaneous chromosomal aberrations, characterized by failures in the system to repair of DNA interstrand crosslinks, which confers hypersensitivity to clastogenic agents. As a result, besides clinical signs, laboratory tests are employed for diagnostic purposes of Fanconi Anemia.

The current routine laboratory tests commonly use toxic chemical agents to induce chromosomal aberrations in peripheral blood lymphocytes, such as diepoxybutane (DEB) or mitomycin C (MMC), which induces much more chromosomal alterations and breaks in FA cells than in cells from non-FA individuals. ${ }^{4}$

On the other hand, ionizing radiation (IR) is a DNA-damaging physical agent, and studies have been evaluating the effects of IR on peripheral blood lymphocytes of Fanconipositive patients, with results either inconclusive or needing further improvements. ${ }^{5-9}$ The process of irradiation directly influences the types and frequencies of chromosomal aberrations (CA), such as the type of irradiation source, dose, and dose-rates. Thus, the comparison of those researches is not straightforward since they generally employ different irradiation strategies.

The frequency of CA in circulating lymphocytes of human blood is the most extensively studied bioindicator of individual exposure to ionizing radiation. ${ }^{10-12}$ The methodology so-called biological dosimetry is applied in the investigation of induced biological endpoints to correlate them with radiation dose. ${ }^{13,14}$ The scoring of chromosome aberrations from peripheral blood samples is the most reliable method to evaluate real or suspect individual exposure to ionizing radiation. The recommended methods for biological dosimetry may provide a baseline for investigation of chromosomal fragility using ionizing radiation as clastogenic agent.

In this context, this work was designed to evaluate the feasibility of a new approach for chromosomal fragility test towards the diagnosis of Fanconi Anemia, replacing $D E B / M M C$ by ionizing radiation as a clastogenic agent, following the guidelines of the International Atomic Energy Agency ${ }^{14}$ as for biological dosimetry. 


\section{MATERIAL AND METHODS}

\subsection{STUDY POPULATION AND ETHICAL ASPECTS}

The present study was conducted with two groups: 14 DEB-sensitive patients diagnosed with Fanconi anemia, and 14 healthy individuals with a negative DEB test (control), aged from 6 to 18 -year-old (mean age 11.5 years). None of them underwent medical procedures involving IR or mutagenic chemicals, at least three months before this study. This research complied with the Declaration of Helsinki and was performed following recommendations of the Committee of Ethics in Research involving Humans at the Health Sciences Center of the Federal University of Pernambuco ( $\left.n^{\circ} 196555\right)$. All children's parents were informed about the purpose of this study, after which written consent was provided.

\subsection{BLOOD SAMPLES AND IRRADIATION SETUP}

From each volunteer, a sample was obtained by venipuncture in heparinized tubes. The total sample was divided into two aliquots: one was kept as control (non-irradiated), while the other one was irradiated and analyzed based on the patented methodology for scoring unstable chromosomal aberrations in lymphocyte (Deposit n BR10 2013 0256684). The irradiation consisted of X-rays from a 6 MV linear accelerator (Siemens, Primus, USA) at a dose rate of 2 Gy.min. ${ }^{1}$ Syringes ( $3 \mathrm{~mL}$ ) were positioned in a solid waterequivalent phantom $\left(\rho=0.99 \mathrm{~g} \cdot \mathrm{cm}^{-3}\right)$, which simulated soft tissues of the human body. The blood samples were placed in the center of a $15 \times 15 \mathrm{~cm}$ radiation field at a sourcesample distance of $0.80 \mathrm{~m}$ from the radiation source at the phantom, as shown in Figure 1 , and received $2 \mathrm{~Gy}$. 


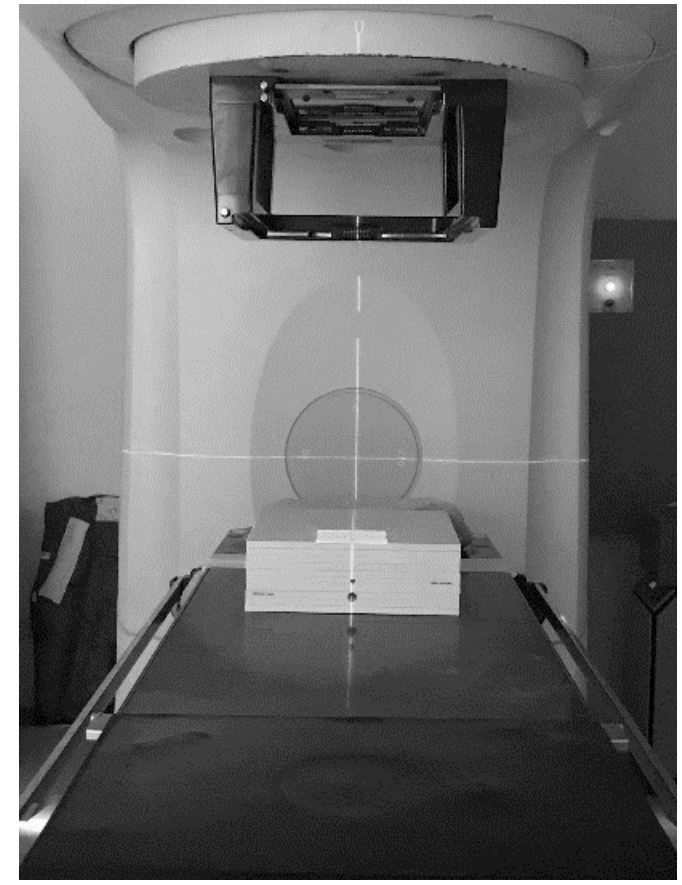

Figure 1 - Setup of blood sample irradiation

After irradiation, the sample was kept at $37{ }^{\circ} \mathrm{C}$ in a water bath for 2 hours, before setting up lymphocyte cultures. For each culture, $0.4 \mathrm{~mL}$ of whole blood was added to $4 \mathrm{~mL}$ RPMI 1640 medium supplemented with $0.5 \mathrm{~mL}$ fetal calf serum (Cultilab, Brazil), and $0.1 \mathrm{~mL}$ phytohemagglutinin (Gibco, Brazil). The cultures were incubated at $37^{\circ} \mathrm{C}$ in humidified air with $5 \% \mathrm{CO} 2$ for $48 \mathrm{~h}$. These procedures were consistent with the guidelines of the International Atomic Energy Agency manual. ${ }^{14}$

\subsection{SLIDE PREPARATION AND CA SCORING}

The slides were prepared as described by Henegariu and coworkers, ${ }^{15}$ with some modifications. Metaphase spreads were stained with $5 \%$ Giemsa solution and air-dried. For chromosomal aberration scoring, 200 complete metaphase cells were counted per sample. In addition to dicentrics, three other groups of chromosomal aberrations were also considered: breakage and failures; fragments; radial configurations. Slides from each culture were analyzed through conventional light microscopes (Leica DME 13595, Germany). 


\subsection{STATISTICAL ANALYSES}

The t-test (for small samples, at the significant level of $5 \%$ ) was employed to establish the confidence intervals of the frequencies of chromosomal aberrations.

\section{RESULTS}

Figure 2 points out a typical chromosomal radial formation (arrow), a kind of chromosomal aberration that is not found in metaphases cells in samples of healthy individuals.

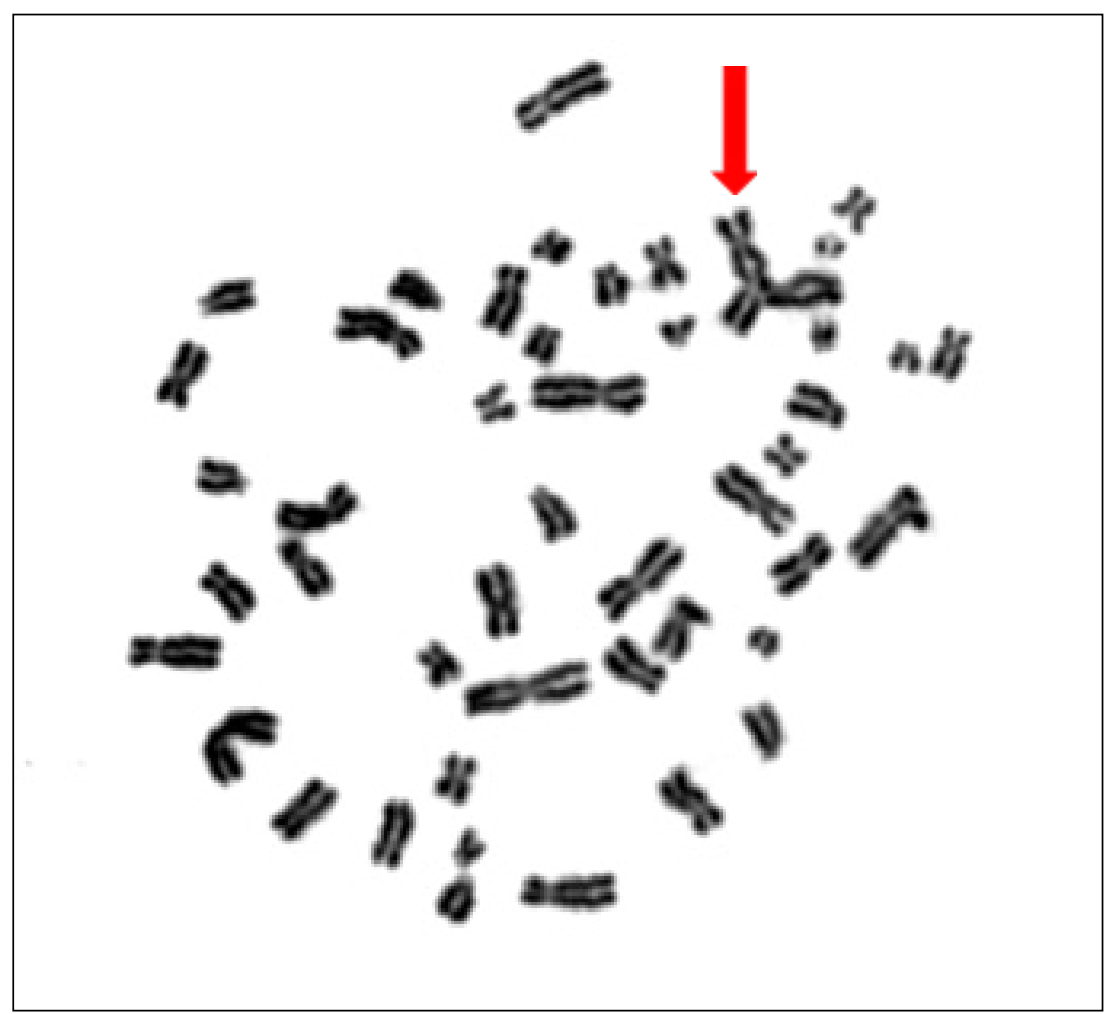

Figure 2 - Metaphase presenting a radial formation (arrow)

Table 1 resumes confidence interval obtained for the frequencies of chromosomal aberrations using t-student distribution in small samples, for normal and DEB-sensitive (FA) subjects. 
Table 1 - Confidence intervals (t-Student, $\alpha=0.05$ ) of the frequency of chromosomal aberration (CA) for each study group

\begin{tabular}{lrr}
\hline \multirow{2}{*}{ Chromosomal Aberrations } & \multicolumn{2}{c}{ Confidence intervals of CA (\%) } \\
\cline { 2 - 3 } & Normal & FA subjects ${ }^{*}$ ) \\
\hline Dicentrics & $14.4-18.3$ & $6.1-13.3$ \\
Breakage and failures & $1.1-2.7$ & $9.4-20.4$ \\
Fragments & $6.0-11.2$ & $11.8-16.1$ \\
Radial formations & not found & $2.0-8.3$ \\
\hline Note: $\left(^{*}\right)$ DEB sensitive. & &
\end{tabular}

\section{DISCUSSION}

According to Table 1, and compared to healthy subjects, the results for DEBsensitive individuals reveal a decrease of dicentrics and a rise of breakage, fragments, and complex chromosomal figures. This pattern of distribution for FA patients was already expected. The irradiation process results in several DNA damages, where double-strand breaks (DSBs) are the most serious ones.

In normal cells, homologous recombination (HR) and non-homologous endjoining (NHEJ) are the two major recombination pathways to DNA repair. ${ }^{9} \mathrm{HR}$ acts in the late $\mathrm{S}$ and $\mathrm{G} 2$ phases, while the DNA-repair by NHEJ is predominant in the remaining phase of the cell cycle. ${ }^{9}$ Thus, failures in the HR and NHEJ mechanisms, which identify and attempt to repair radioinduced DNA-damage, will reflect in a decrease in the frequency of dicentrics, followed by an increase in the number of other chromosomal alterations, with, eventually, the formation of more complex structures as well, such as radial chromosomes (also referred as tri-radial, quadri-radial, and rearrangements).

Figure 2 presents a typical example of complex chromosomal aberration (radial formation). In this case, a tri-radial (indicated by an arrow in that figure). This kind of alteration is not commonly found in studies involving biological dosimetry from samples of normal subjects. The appearance of such complex chromosomal structures in metaphase slides is directly linked to the hypersensitivity of AF subjects to ionizing radiation and associated with genomic instability, which is responsible for chromosomal fragility.

In biological dosimetry, dose-effect relationships obtained after in vitro irradiation of blood can be used as a calibration curve to estimate the absorbed dose from irradiation in vivo. ${ }^{14,16}$ Generally, frequencies of dicentrics are correlated to radiation doses, which depend 
on radiation quality (or LET-Linear Energy Transfer) and relative biological effectiveness (RBE). However, in the assessment of absorbed doses from the same irradiated blood sample, interlaboratory variations are quite common.

These variations arise from several reasons such as environmental conditions of each laboratory, choice of reagents, handling procedures and equipment, and the level of training for the subjective nature of microscopic identification of unstable chromosome alterations. ${ }^{17}$ Hence, the International Atomic Energy Agency recommends that each cytogenetic laboratory should generate its own dose-response curve in order to perform biodosimetry. ${ }^{14}$ Similarly to biological dosimetry assays, using the methodology here proposed for the diagnosis of FA by the irradiation of blood sample, there might be some interlaboratory fluctuations regarding confidence intervals of the chromosomal aberrations presented in this study.

FA subjects present an extensive phenotypic variability and may also present severe degrees to mild in distinct patients. Patients presenting a mild clinical picture are classified as AF mosaic (with a 30\% incidence of patients with AF) for carrying affected and unaffected cells in the same tissue. This occurs by spontaneous reversal of one of the mutated alleles in hematopoietic lymphocytes ${ }^{3,4,18}$. Naturally, further studies employing the methodology carried out here should be performed with different degrees of FA subjects, for evaluating their influence over the frequency of chromosomal aberrations.

Furthermore, to diagnose diseases associated with chromosomal fragility, current laboratory tests employ toxic chemical agents (DEB/MMC), which are potential carcinogens, and precautions should be taken when handling these compounds. Therefore, the use of these compounds has several restrictions on their acquisition, transport, manipulation, and disposal. However, the methodology proposed in this work uses standard safety procedures for sample irradiation, followed by well-known cell culture protocols for metaphase analyses of lymphocytes. As implemented in this study, blood samples of patients could be irradiated in a hospital RT department, and then sent to a cytogenetics laboratory. 


\section{CONCLUSION}

This work, which is fundamentally based on the biological dosimetry knowledge, paves the way to an alternative, safe, and affordable methodology of a laboratory test for diagnosis of Fanconi anemia.

\section{CONFLICTS OF INTERESTS}

The authors declare that there is no conflicts of interests.

\section{ACKNOWLEDGMENTS}

This work was supported by Conselho Nacional de Desenvolvimento Científico e Tecnológico (CNPq - Brazil - Grant $n^{\circ}$ 308467/2015-9) and the International Atomic Energy Agency (IAEA - Austria - Research Contract $n^{\circ} 22266$ ).

\section{REFERENCES}

1. Gordon EC, Rutherford TR. Fanconi anaemia-constitutional, familial aplastic anaemia. Bailleres Clin Haematol. 1989;2:139-51.

2. Auerbach AD. Fanconi anemia and its diagnosis. Mutat Res. 2009;668:4-10.

3. Fargo JH, Rochowski A, Giri N, Savage SA, Olson SB, Alter BP. Comparison of Chromosome Breakage in Non-Mosaic and Mosaic Patients with Fanconi Anemia, Relatives, and Patients with Other Inherited Bone Marrow Failure Syndromes. Cytogenet Genome Res. 2014;144(1):15-27.

4. Auerbach AD. Diagnosis of Fanconi anemia by diepoxybutane analysis. Curr Protoc Hum Genet. 2015 Apr 1;85(1):8.7.1-8.7.17. 
5. Dextraze ME, Gantchev T, Girouard S, Hunting D. DNA interstrand cross-links induced by ionizing radiation: an unsung lesion. Mutat Res. 2009;704(1-3):101-7.

6. Saraswathy R, Natarajan AT. Frequencies of X-ray induced chromosome aberrations in lymphocytes of xeroderma pigmentosum and Fanconi anemia patients estimated by Giemsa and fluorescence in situ hybridization staining techniques. Int J Genet Mol Biol. 2000;23(4):893-99.

7. Barquinero JF, Barrios L, Ribas M, Egozcue J, Caballin MR. Cytogenetic sensitivity of three Fanconi anemia heterozygotes to bleomycin and ionizing radiation. Cancer Genet Cytogenet. 2001;124:80-83.

8. Mohseni-Meybodi A, Mozdarani H, Vosough, P. Cytogenetic sensitivity of GO lymphocytes of Fanconi anemia patients and obligate carriers to mitomycin $\mathrm{C}$ and ionizing radiation. Cytogenet Genome Res. 2007;119(4):191-5.

9. Francies FZ, Wainwright R, Poole J, De Leeneer K, Coene I, Wieme G, et al. Diagnosis of Fanconi Anaemia by ionising radiation- or mitomycin C-induced micronuclei. DNA Repair (Amst). 2018;61:17-24.

10.Bender MA, Awa AA, Brooks AL, Evans HJ, Groer PG, Littlefield LG, et al. Current status of cytogenetic procedures to detect and quantify previous exposures to radiation. Mutat Res. 1988;196:103-59.

11. Lloyd DC, Edwards AA, Prosser JS. Chromosome aberration induced in human lymphocytes by in vitro acute $x$ gamma radiation. Radiat Prot Dosim. 1986;15:83-88.

12. Lemos-Pinto MM, Santos NF, Amaral A. Current status of biodosimetry based on standard cytogenetic methods. Radiat Environ Biophys. 2010;49(4):567-81.

13. Amaral A. Trends in biological dosimetry: an overview. Braz Arch Biol Tech. 2002;45:119-24.

14. International Atomic Energy Agency. Cytogenetic dosimetry: applications in preparedness for and response to radiation emergencies. Vienna: Scientific and Technical Publications; 2011. 
15. Henegariu O, Heerema NA, Lowe WL, Bray-Ward P, Ward DC, Vance GH. Improvements in cytogenetic slide preparation: controlled chromosome spreading, chemical aging and gradual denaturing. Cytometry. 2001;43:101-9.

16. Doloy MT, Malarbet JL, Guedeney G, Bourguignon M, Leroy A, Reillaudou M, et al. Use of unstable chromosome aberrations for biological dosimetry after the first postirradiation mitosis. Radiat Res. 1991;125:141-51.

17. Lemos-Pinto MM, Cadena M, Santos N, Fernandes TS, Silva EB, Amaral A. Dose-response curve for biodosimetry from a $6 \mathrm{MV}$ electron linear accelerator. Braz J Med Biol Res. 2015;48(10):908-14.

18. Oostra AB, Nieuwint AWM, Joenje H, Winter JP. Diagnosis of Fanconi Anemia: Chromosomal Breakage Analysis. Anemia. 2012;2012:1-9.

Recebido em: 17 de setembro de 2019 Avaliado em: 9 de outubro de 2019 (Avaliador A) Aceito em: 10 de outubro de 2019 
